\title{
Atypical antipsychotics in bipolar disorder: the treatment of mania
}

\author{
John Cookson
}

\begin{abstract}
The development of atypical antipsychotics has stimulated research on the treatment of mania. Several well-established options now exist for monotherapy of mania. None of the atypicals has shown greater efficacy than haloperidol in improving manic symptoms, but they all produce fewer extrapyramidal sideeffects and they may differ in their effects on depressive symptoms. Combinations of an antipsychotic with lithium or valproate offer further options, with somewhat greater efficacy in treating mania but also with more side-effects.
\end{abstract}

Mania is a clearly defined condition that can present in different levels of severity, varying from the mild (hypomanic) to the florid, raging and psychotic. Only the mildest forms can be left untreated without risking harm to either the patient's welfare, relationships and job, or to the well-being of those who are close to them (relatives, carers and mental health professionals). The milder forms may be accompanied by high levels of energy, productivity and creativity. But even these carry a risk of subsequently switching into a phase of depression and incapacity that might have been avoided by treatment of the preceding hypomania. Severe forms constitute a psychiatric emergency, demanding immediate control, including rapid tranquillisation with medication. Mania is one of the most insightless forms of mental disorder and for treatment to be very useful it must be not only effective but also acceptable to the patient, easy to use and not produce unpleasant side-effects (Cookson, 2007).

Surveys of clinical practice have shown that antipsychotics are the most commonly used drugs for patients hospitalised with mania, whether in Britain, Scandinavia, other parts of Europe or North America. Classical (typical) antipsychotics produce unpleasant extrapyramidal side-effects such as akathisia, dystonia and parkinsonism, which (although partially preventable by anticholinergic medication) are resented by patients and limit their adherence to treatment. It is therefore very important to know whether the use of antipsychotics in mania is justified by evidence of efficacy and whether newer antipsychotics with fewer unpleasant acute side-effects are also effective in mania.

\section{Mechanisms of antimanic actions of antipsychotics}

It is thought that antipsychotics owe their antimanic effects mainly to blockade dopamine receptors, but additionally to some extent to blockade of noradrenaline at $\alpha_{1}$ receptors (as in the case of haloperidol), and blockade of histamine at $\mathrm{H}_{1}$ receptors (causing sedation as in the case of chlorpromazine) (Peroutka \& Snyder, 1980; Cookson, 2001). Some atypical antipsychotics (e.g. olanzapine, quetiapine, risperidone) share all these actions as well as being potent blockers of serotonin receptors, but are selective for sub-types of dopamine receptors; others (amisulpride) block only sub-types of dopamine receptors. Blockade of serotonin (5-hydroxytryptamine, 5-HT) at 5- $\mathrm{HT}_{2 \mathrm{~A}}$ receptors is of unclear importance in mania. It cannot be assumed that drugs effective in schizophrenia will be effective in mania or vice versa.

\section{Assessing the evidence}

To prove that a drug is efficacious for a psychiatric condition, it is essential to show that it is superior to placebo, by conducting randomised doubleblind placebo-controlled trials. The challenges of conducting such trials in mania have been met only in recent years, in the course of developing novel anticonvulsant and atypical antipsychotic treatments in trials since 1994. These trials are therefore providing answers to questions that have long remained unresolved about the treatment of

John Cookson is a consultant psychiatrist at the East London Foundation Trust (Mile End Hospital, London E1 4DG, UK. Email: john. cookson@eastlondon.nhs.uk). He has had a career-long interest in psychopharmacology and in bipolar disorder, and has authored two editions of Use of Drugs in Psychiatry published by Gaskell. 
mania. Analysis of the results of these trials requires attention not only to the statistical significance of differences in special rating scales, but also to the size of the effect, and to the generalisability of results derived from highly selected patients in clinical trials centres to patients with mania in routine practice. It is also important to consider how drop-outs from the studies may have biased the interpretation of results.

\section{'Acute' or 'rapid' tranquillisation}

Treatment of mania may begin with control of the agitated patient by 'acute' or 'rapid' tranquillisation (Cookson, 2006). This involves an antipsychotic or a benzodiazepine or a combination of these, which may have to be given intramuscularly. Two placebocontrolled trials have investigated the response of patients with mania to intramuscular medication. The first showed improvement within $20 \mathrm{~min}$ and greater improvement with the antipsychotic (olanzapine $10 \mathrm{mg}$ ) than with the benzodiazepine (lorazepam $2 \mathrm{mg}$ ) over $2 \mathrm{~h}$ (Meehan et al, 2001). The second showed improvement with both lorazepam ( $2 \mathrm{mg}$ ) and aripiprazole (9.75-15 mg) but a trend towards greater improvement with lorazepam (Zimbroff et al, 2007). By contrast, intravenous valproate $(20 \mathrm{mg} / \mathrm{kg}$ ) was not associated with an improvement in mania within $2 \mathrm{~h}$ (Phrolov et al, 2004), suggesting a different mechanism of action.

Once calmed, most patients then require treatment over a period of 2-4 weeks with oral medication to achieve a more gradual further improvement.

\section{Monotherapy comparisons with placebo in mania}

Table 1 lists the drugs that have been proved superior to placebo as monotherapy in such trials lasting 3-6 weeks. To grant a licence to market a drug for mania, most authorities, including the European Medicines Agency, require two trials performed at independent centres. Less well-proven, but probably effective, is clozapine (Suppes et al, 1999). In addition, one can conclude from negative trials that certain drugs do not improve mania; these are topiramate, gabapentin and lamotrigine.

\section{Lithium, valproate or antipsychotics for mania}

The first drug to be proved efficacious in such trials was valproate (Pope et al, 1991; Bowden et al, 1994). Although Tables 2 and 3 show that the drug with

\begin{tabular}{lc}
$\begin{array}{l}\text { Table } 1 \text { Drugs shown to improve mania as mono- } \\
\text { therapy in randomised placebo-controlled trials }\end{array}$ \\
\hline Drug & Positive trials, $n$ \\
\hline Valproate & 2 \\
Lithium & 5 \\
Haloperidol & 3 \\
Olanzapine & 2 \\
Risperidone & 3 \\
Quetiapine & 2 \\
Ziprasidone & 2 \\
Aripiprazole & 2 \\
Carbamazepine & 2 \\
Tamoxifen & 2
\end{tabular}

most trials (not all published) proving efficacy is lithium, this drug is not usually sufficiently rapid in onset to be useful as monotherapy (Bowden et al, 1994). The trials of carbamazepine (Weisler et al, 2004, 2005) and aripiprazole (Sachs et al, 2006) are more recent. Tamoxifen, an anti-oestrogen, widely used for breast cancer, has antimanic properties that were first investigated because this drug shares with lithium and valproate the ability to block the intracellular second messenger system protein kinase-C, through which certain transmitters act (Zarate et al, 2007; Yildiz et al, 2008). Although haloperidol has been the favourite drug of clinicians for treating mania (Chou et al, 1996; Cookson, 2001), it is only in the course of comparative trials with risperidone (Smulevich et al, 2005) and quetiapine (McIntyre et al, 2005), and more recently aripiprazole, that haloperidol has been proved conclusively to be efficacious. Apart from haloperidol, most evidence for efficacy in mania now concerns the atypical antipsychotics olanzapine, risperidone, quetiapine, ziprasidone and aripiprazole. Questions arise about the relative efficacy of these drugs compared with either haloperidol or valproate, and whether they should be used initially as monotherapy or combined with valproate or lithium. Also, since treatment often needs to commence with rapid tranquillisation, and only three atypicals can be given intramuscularly (recently olanzapine and in some countries ziprasidone and aripiprazole), haloperidol remains widely used despite its propensity to cause unpleasant extrapyramidal side-effects.

\section{Randomised placebo-controlled trials of atypical antipsychotics}

The published trials are summarised in Table 2, using a 'number needed to treat' (NNT) analysis 
Table 2 Monotherapy with atypical antipsychotics in mania: numbers needed to treat (NNTs) in placebo-controlled parallel-group randomised trials

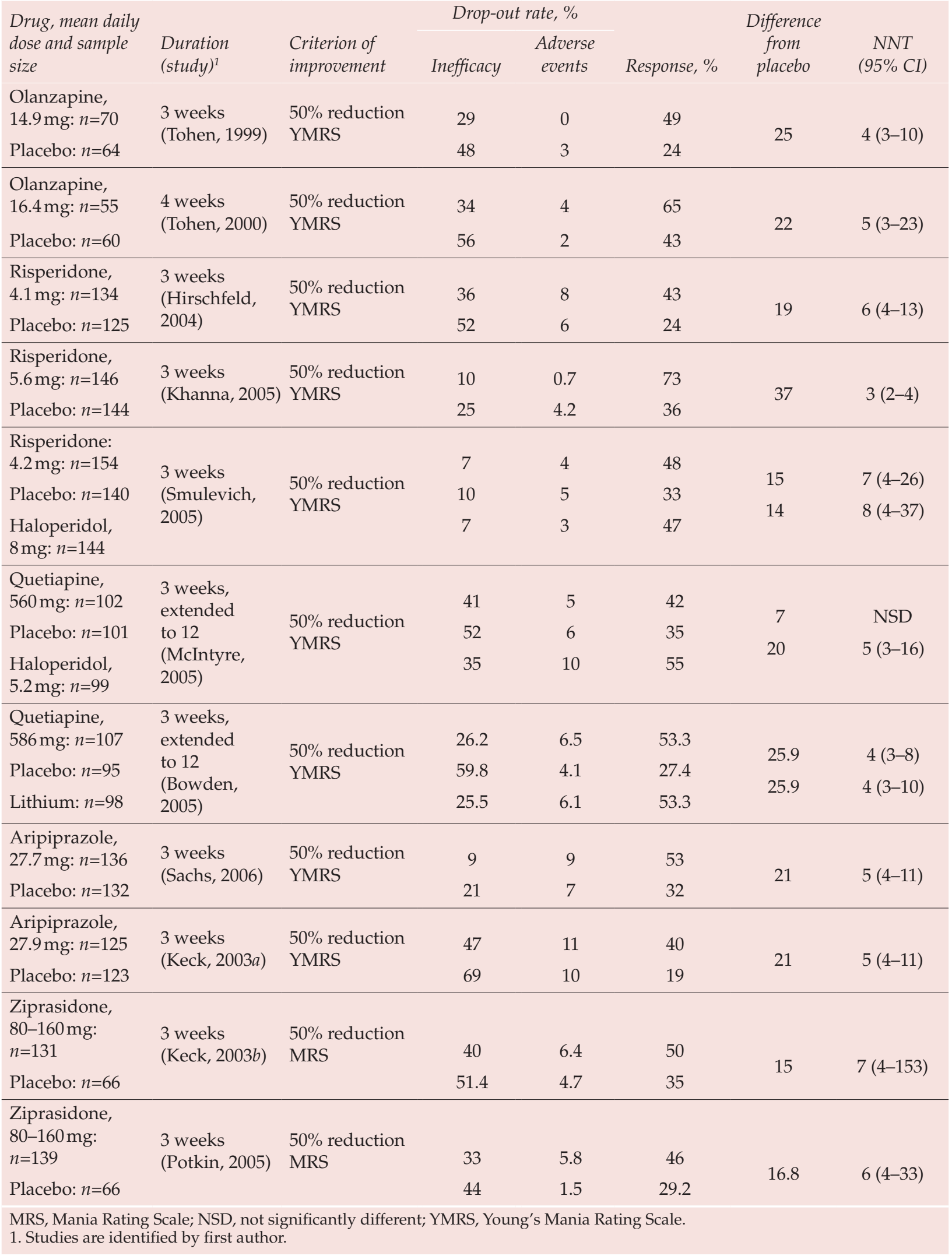

of size of effect. Number needed to treat is calculated by dividing the difference in response rate between active drug and placebo into 100 and correcting to the next highest integer. It represents the number of patients who must be treated for one patient to achieve the defined response as a 
result of the pharmacological effect of the drug. In this instance the response was usually a 50\% reduction in score on the 11-item Young's Mania Rating Scale (YMRS; Young et al, 1978) - a scale that clinicians may find helpful for monitoring the progress of in-patients with mania. The NNT thus provides a measure of the size of effect that can be expected of the drug in a clinical situation, and it may be more clinically meaningful than the statistically more precise measure known as 'effect size'. For a drug to be useful monotherapy as a first-line treatment in a common and severe disorder such as mania, the NNT for $50 \%$ improvement in severity should be in the order of 2-4 (Cookson et $a l, 2002)$.

Most studies were of 3 or 4 weeks duration and there was a placebo response rate of $19-43 \%$, reflecting the effects of a variety of possible non-specific factors such as hospitalisation, extra medication with benzodiazepines or chloral allowed during the first 10 days, and bias in the raters. Drop-out rates for inefficacy ranged from 10 to $69 \%$ on placebo, and from 7 to $47 \%$ on active drug. Drop-out rates for adverse events (including suspected side-effects) ranged from 1.5 to $10 \%$ on placebo, and from 0 to $11 \%$ on atypical antipsychotic; on haloperidol the drop-out rates for lack of efficacy were 7 and $35 \%$, and for adverse events 3 and 10\%. In some studies patients dropped out at their own request with no clear reason. Total drop-out rates ranged from 15 to $79 \%$ on placebo, from 11 to $58 \%$ on atypical antipsychotic, and were 10 and $45 \%$ on haloperidol and $32 \%$ on lithium (Table 2 ). When making comparisons between groups, loss of a participant through drop-out is usually dealt with by carrying forward the rating at the last observed time before drop-out. This method of analysis ('last observation carried forward' or LOCF) introduces a bias against any treatment, including placebo, that is associated with a high rate of drop-outs. The study with the lowest rate of drop-out on active treatment was the study of risperidone conducted in India (Khanna et al, 2005). It is likely that all other studies underestimated the extent of antipsychotic efficacy.

\section{Olanzapine}

Olanzapine was the first of the atypical antipsychotics to be proved efficacious in mania (Tohen et al, 1999, 2000). Patients with mixed mania were also included in these trials. The starting doses in the two studies were $10 \mathrm{mg}$ and $15 \mathrm{mg}$, and the mean modal doses (modal dose for each patient, averaged for each therapy) were 14.9 and $16.4 \mathrm{mg}$ /day. The most common side-effects were somnolence (22\% more than placebo), dry mouth (15\% more), dizziness (12\% more), weakness (9\% more) and weight gain (10\% more). The problem of weight gain is more obvious in adolescents: a later study (Tohen et al, 2007) recorded gain in $41.9 \%$ on olanzapine $v .1 .9 \%$ on placebo.

\section{Risperidone}

In the trial of Hirschfeld et al (2004), risperidone was increased gradually over 4 days to a maximum of $6 \mathrm{mg} /$ day. The NNT was 6 (95\% CI 4-13). Sideeffects on risperidone were somnolence $(28 \% v .7 \%$ on placebo) and hyperkinesias (parkinsonism) in $16 \%$ v. $5 \%$.

The study by Khanna et al (2005) was distinguished by relatively high YMRS scores on entry (mean score 37 ; about $30 \%$ higher than in most other studies of atypical antipsychotics in mania), and by a high rate of study completion on risperidone with low dropout rates, particularly for lack of efficacy. The mean modal dose was $5.4 \mathrm{mg} /$ day. The rate of response on risperidone was highest in this study and the NNT was impressively low at 3. Extrapyramidal side-effects occurred in $35 \%$ of those on risperidone and $6 \%$ on placebo.

The study by Smulevich et al (2005) had a slower dosing schedule, reaching a maximum of $6 \mathrm{mg} /$ day by day 5 . It also had a haloperidol comparator group with a mean modal dose of $8 \mathrm{mg} /$ day (see below). Both active drugs were effective compared with placebo from day 7. By day 21 the NNT for $50 \%$ improvement was 7 for risperidone and 8 for haloperidol. Side-effects on risperidone included extrapyramidal symptoms $(17 \%$, compared with $40 \%$ for haloperidol and $95 \%$ for placebo).

\section{Quetiapine}

The two trials of monotherapy excluded patients with mixed mania. Significant efficacy at 3 weeks was observed in one study and in the combined analysis (Vieta et al, 2005). Patients who responded to quetiapine were usually receiving $600 \mathrm{mg} /$ day or more. The dose was increased towards this over 5 days and then to a maximum of $800 \mathrm{mg} /$ day. The most common side-effects were somnolence, dry mouth, weight gain and dizziness.

\section{Ziprasidone and aripiprazole}

Aripiprazole is the most recent atypical antipsychotic to be licensed in the UK for the treatment of mania. Ziprasidone is not yet licensed for use in the UK. In the studies of aripiprazole and ziprasidone, additional sedation with lorazepam in the relatively high doses of up to 6 and $8 \mathrm{mg} /$ day respectively was permitted for the first 4 days, implying a feared lack of rapid efficacy and control of agitation. For both these drugs the main advantages may be in 
Table 3 Monotherapy with other antimanic drugs in mania: numbers needed to treat (NNTs) in placebo-controlled parallel-group randomised trials

\begin{tabular}{|c|c|c|c|c|c|}
\hline $\begin{array}{l}\text { Drug, mean daily dose and } \\
\text { sample size }\end{array}$ & $\begin{array}{l}\text { Duration } \\
(\text { study })^{1}\end{array}$ & $\begin{array}{l}\text { Criterion of } \\
\text { improvement }\end{array}$ & $\begin{array}{c}\text { Response, } \\
\%\end{array}$ & $\begin{array}{c}\text { Difference } \\
\text { from placebo }\end{array}$ & $\begin{array}{l}\text { NNT, mean } \\
(95 \% \mathrm{CI})\end{array}$ \\
\hline Valproate, $^{2} n=20$ & \multirow{2}{*}{$\begin{array}{l}3 \text { weeks } \\
\text { (Pope, 1991) }\end{array}$} & \multirow{2}{*}{$\begin{array}{l}50 \% \text { reduction } \\
\text { YMRS }\end{array}$} & 45 & \multirow{2}{*}{36} & \multirow{2}{*}{$3(2-9)$} \\
\hline Placebo, $n=23$ & & & 9 & & \\
\hline Valproate, $^{2} n=63$ & \multirow{4}{*}{$\begin{array}{l}3 \text { weeks } \\
\text { (Bowden, 1994) }\end{array}$} & \multirow{4}{*}{$50 \%$ reduction } & 48 & \multirow{2}{*}{23} & \multirow[b]{2}{*}{$5(3-14)$} \\
\hline Placebo, $n=73$ & & & 25 & & \\
\hline & & & & \multirow{2}{*}{24} & \multirow{2}{*}{$5(3-22)$} \\
\hline Lithium, ${ }^{1} n=35$ & & & 49 & & \\
\hline $\begin{array}{l}\text { Lamotrigine, } 200 \mathrm{mg} / \text { day } \\
n=73\end{array}$ & \multirow{4}{*}{$\begin{array}{l}6 \text { weeks } \\
\text { (Goldsmith, 2003) }\end{array}$} & \multirow{4}{*}{$\begin{array}{l}\text { CGI very much or } \\
\text { much improved }\end{array}$} & 49 & \multirow{4}{*}{$\begin{array}{r}1 \\
18\end{array}$} & \multirow{4}{*}{$\begin{array}{l}\text { NSD } \\
6(3-37)\end{array}$} \\
\hline & & & 49 & & \\
\hline Iaceno, & & & & & \\
\hline Lithium, ${ }^{2} n=/ 6$ & & & 66 & & \\
\hline $\begin{array}{l}\text { Carbamazepine ER, } \\
952 \mathrm{mg} / \text { day, } n=101\end{array}$ & \multirow{2}{*}{$\begin{array}{l}3 \text { weeks } \\
(\text { Weisler, 2004) }\end{array}$} & \multirow{2}{*}{$\begin{array}{l}50 \% \text { reduction } \\
\text { YMRS }\end{array}$} & 41.5 & \multirow[b]{2}{*}{19.1} & \multirow[b]{2}{*}{$5(4-16)$} \\
\hline Placebo, $n=103$ & & & 22.4 & & \\
\hline $\begin{array}{l}\text { Carbamazepine ER, } \\
642 \mathrm{mg} / \text { day, } n=120\end{array}$ & \multirow{2}{*}{$\begin{array}{l}3 \text { weeks } \\
\left(^{\text {Weisler, 2005) }}\right.\end{array}$} & \multirow{2}{*}{$\begin{array}{l}50 \% \text { reduction } \\
\text { YMRS }\end{array}$} & 61 & \multirow{2}{*}{32} & \multirow{2}{*}{$4(3-5)$} \\
\hline Placebo, $n=115$ & & & 29 & & \\
\hline \multicolumn{6}{|c|}{$\begin{array}{l}\text { CGI, Clinical Global Impressions scale; ER, extended release; NNT, number needed to treat; NSD, not significantly different; } \\
\text { YMRS, Young's Mania Rating Scale. } \\
\text { 1. Studies are identified by first author. } \\
\text { 2. Lithium and valproate were dosed to achieve target blood levels. } \\
\text { 3. DSM-IV manic or mixed. }\end{array}$} \\
\hline
\end{tabular}

long-term treatment when their side-effects on weight gain and metabolism are probably superior to other atypicals.

\section{Placebo-controlled monotherapy trials of haloperidol in mania}

Two monotherapy studies have included haloperidol as an active comparator (McIntyre et al, 2005; Smulevich et al, 2005) (Table 2). In the former, the haloperidol dose started at $4 \mathrm{mg} /$ day and was adjusted to $2-12 \mathrm{mg}$ / day by day 5 . The NNT for $50 \%$ improvement by day 21 was 8 . This is far larger than one would expect with the most commonly used antimanic drug of the previous decade. This might be because the mean dose of haloperidol was only $8 \mathrm{mg} /$ day, or because the patients in the trial were in some ways not typical of routine clinic patients and more resistant to treatment.

A comparator group on haloperidol (up to $8 \mathrm{mg} /$ day) was also included in the study by McIntyre et al (2005). At 3 weeks the response rate on haloperidol, on a mean dose of only $5.2 \mathrm{mg} /$ day, was $55 \%$ compared with $35 \%$ on placebo, giving an NNT of 5 . Side-effects in the form of extrapyramidal symptoms were much more common on haloperidol (59.6\%) than on placebo (15.8\%): for example, $33.3 \%$ of participants on haloperidol but only $5.9 \%$ on placebo experienced akathisia. Somnolence occurred more often with haloperidol $(9.1 \%)$ than placebo $(5 \%)$

\section{Patterns of symptom improvement: sedative, antipsychotic or antimanic?}

It had been suggested that antipsychotics owe their effects in mania either to non-specific sedation (that is making the person drowsy or asleep), or to combating psychotic symptoms. However, this view fails to recognise that non-sedative dopamine-blocking drugs can improve mania (Cookson et al, 1981); these would now include aripiprazole and ziprasidone. In all studies of olanzapine and risperidone and in the combined analysis of quetiapine studies, the improvement in mania occurred in patients with or without psychotic symptoms. When individual items of the YMRS were analysed, drug treatment (with olanzapine, quetiapine and presumably the other antipsychotics) improved the whole range 
of symptoms (including elation, flight of ideas, grandiosity, sexual interest, irritability, aggression, general appearance and insight, as well as the items most sensitive to sedation: insomnia, overactivity and pressure of speech). These findings lead to the inevitable conclusion that the drugs are not just antipsychotic, but also antimanic. Interestingly, the symptom of loss of insight is one of the slowest to improve (Tohen et al, 1999). This corresponds to the clinical situation in which a patient treated with antipsychotics for severe mania has improved sufficiently within 3 weeks to appeal successfully to a mental health review tribunal, but still lacks insight into the illness and the benefits of, and need for, treatment.

\section{Depression in mania}

Depressive symptoms are very common during mania, and if amounting to a major depressive syndrome the condition is classified as mixed mania in DSM-IV (American Psychiatric Association, 1994). However, at least 12 forms of bipolar mixed states have been described and are likely to respond differently to treatments (Cookson \& Ghalib, 2005). Some patients develop depressive syndromes after mania has improved ('post-manic depression'), and this is described as a 'switch' into depression.

It has been suggested, but never proved, that classical antipsychotics may worsen or induce depression apartfrom their obvious extrapyramidal side-effects. For example, the use of perphenazine in mania without an anticholinergic drug has been associated with a high rate of development of depressive symptomatology, with accompanying signs of parkinsonism, particularly akinesia (Zarate \& Tohen, 2004). Used in this way for schizophrenia, the older antipsychotics such as haloperidol are known to induce 'akinetic depression', which is best viewed as an extrapyramidal side-effect (van Putten \& May, 1978).

In the trials of atypical antipsychotics in mania, changes in symptoms of depression have usually been monitored. Thus, several antipsychotics have been shown to improve depressive symptoms alongside the improvement in mania; these include olanzapine (Tohen et al, 1999, 2000), risperidone (Khanna et al, 2005), quetiapine and aripiprazole. For example, in one study (Smulevich et al, 2005), depression scores (on the Montgomery-Åsberg Depression Rating Scale, MADRS) fell more on risperidone than on placebo from week 1 , and on haloperidol only from week 2 .

Likewise, on both quetiapine and haloperidol, depression scores improved by day 21 more than on placebo (McIntyre et al, 2005). On the other hand, the switch rates into depression over 12 weeks were similar for haloperidol (8.1\%) and placebo (8.9\%), and tended to be lower for quetiapine (2.9\%).

In patients with mixed mania, both depression (MADRS) and mania scores improved with treatment on olanzapine ( $v$. placebo) used either as monotherapy (Baker et al, 2003) or as an adjunct to lithium or valproate (Baker et al, 2004).

\section{Comparative RCTs of anti- psychotics in mania without placebo: haloperidol $v$. atypicals}

In a comparative trial in mania, in which additional lorazepam was permitted, risperidone showed similar efficacy to haloperidol or lithium (Segal et al, 1998).

In the largest randomised comparative study of haloperidol(Tohen et al, 2003), it was compared with olanzapine over 6 and 12 weeks. Among patients on haloperidol (up to $15 \mathrm{mg}$ /day, at week 6 mean dose $7 \mathrm{mg}$ /day), the proportion responding $(50 \%$ reduction in YMRS score) by 6 weeks was $74 \%$. The proportion showing syndromal remission (according to DSM-IV) was $44 \%$, a figure similar to that found on haloperidol in consecutive admissions for mania by Rifkin et al (1994).

In patients with low levels of depressive symptoms at commencement on haloperidol, a total of $16.8 \%$ switched into depression within 12 weeks. However, as there was no placebo group, it is not clear whether this represents the natural history of the patients' mood cycles, perhaps accelerated by effective treatment of mania, or some additional depressant effect of haloperidol. The switch rate among patients on olanzapine was nonsignificantly lower at 12 weeks $(9.4 \%)$, although the switch to depression occurred significantly sooner with haloperidol (Tohen et al, 2003).

Thus, both olanzapine and quetiapine tended to produce a lower rate of switching into depression than did haloperidol. Both drugs (in the doses used) seemed also to lead to slower improvement in mania than did haloperidol. There is also the problem that haloperidol is prescribed in doubleblind trials without a prophylactic anticholinergic drug, and is therefore liable to induce 'akinetic depression', as described by van Putten \& May (1978) in schizophrenia. When this occurs, some studies allow that an anticholinergic be added; others discontinue the patient from the trial.

These studies confirm the efficacy of haloperidol in reducing the symptoms of mania. None of the newer drugs has been shown to be more effective in this regard. Most (risperidone is the exception) appear to be less effective than haloperidol (Scherk et al, 2007). However, the doses used in the 
trials for both the atypical antipsychotics and for haloperidol may be less than sufficient to produce optimal improvement. The clear superiority of the newer antipsychotics is that they produce far fewer extrapyramidal side-effects than haloperidol. For example, the very unpleasant side-effect of akathisia was reported by $30 \%$ of patients on haloperidol and $6 \%$ on olanzapine.

\section{Trials of atypical antipsychotics v. valproate in mania}

Olanzapine (Tohen et al, 2002, 2003; Zajecka et al, 2002), quetiapine (Del Bello et al, 2006) and haloperidol (McElroy et al, 1996) have been compared directly with valproate. The improvement was slightly faster and slightly greater with olanzapine (average doses 17.4 and $14.7 \mathrm{mg} /$ day) than with semisodium valproate (1401 and $2115 \mathrm{mg}$ /day). Interestingly, this superiority of olanzapine over valproate was seen only in patients with non-psychotic mania (Tohen et $a l, 2002)$. Olanzapine and valproate seemed equally effective in psychotic mania as they did in mixed mania.

A comparison of quetiapine with valproate in adolescents with mania also showed superiority of the antipsychotic (Del Bello et al, 2006).

Apart from speed of action, which is greater with antipsychotics, there are differences in side-effects. Olanzapine produced more somnolence (39\% v. $21 \%$, and $47 \%$ v. $29 \%$ ), dry mouth ( $34 \%$ v. $6 \%$ ), running nose $(14 \%$ v. $3 \%)$, oedema ( $14 \%$ v. $0 \%)$, increased appetite $(12 \%$ v. $2 \%)$ and weight gain $(12 \%$ v. $7.9 \%$, and $25 \% v .10 \%$ ), whereas valproate produced more gastrointestinal disturbance with nausea $(29 \% v$. $10 \%$ ). Other side-effects of valproate and olanzapine occur but are too rare to have been detected in these trials.

The study of psychotic mania by McElroy et al (1996) indicated that if a sufficiently large dose of valproate (as semisodium valproate $20 \mathrm{mg} / \mathrm{kg} /$ day) is used from the start, a similar improvement occurs with valproate or haloperidol $(0.2 \mathrm{mg} / \mathrm{kg} /$ day $)$. However, the generalisability of this finding may be limited, since haloperidol did not show its usual rapid onset of effect. Furthermore, a second study of valproate loading by Hirschfeld et al (1999) showed a delay of about $48 \mathrm{~h}$ in onset of the antimanic effect with valproate.

\section{Monotherapy or combination treatment}

Since lithium and valproate are thought to have mechanisms of action other than receptor blockade, and probably reduce dopamine release, it may be expected that combination of an antipsychotic with lithium or valproate will produce a greater antimanic effect. This has been confirmed in trials in which an antipsychotic or placebo was given in addition to lithium or valproate. The effect is clearest when patients had previously shown only partial response to the lithium or valproate. The antipsychotics for which this added benefit has been shown are olanzapine, risperidone, quetiapine and aripiprazole, but not ziprasidone (Scherk et al, 2007). The contrary situation in which valproate or placebo has been added to an antipsychotic that patients were already receiving has been reported in only one study (Muller-Oerlinghausen et al, 2000).

Two earlier trials found carbamazepine together with a typical antipsychotic more effective than an antipsychotic alone (Klein et al, 1984; Moller et al, 1989). However, more recent trials failed to find a benefit of adding risperidone or olanzapine to carbamazepine (Yatham et al, 2003; Tohen et al, 2008); in the latter trial a high dose of olanzapine was given to counter the increased metabolism due to hepatic enzyme induction on carbamazepine.

\section{Conclusions}

All the atypical antipsychotics that have been studied in rigorous randomised controlled trials in mania have been shown to be superior to placebo. Of the commonly used drugs, only amisulpride has not been studied in this way.

The clinical trials of atypical antipsychotics in mania, sponsored by the pharmaceutical manufacturers, have answered many important questions about bipolar disorder that had been unresolved for 50 years. In particular, they have shown that antipsychotics generally have specific antimanic properties that are independent of sedation or psychosis. The speed of action and size of effect of antipsychotics makes them especially useful for control of emergent (hypomanic) symptoms and for acute tranquillisation in mania. None of the atypicals is more effective than haloperidol in reducing manic symptoms, but all produce fewer extrapyramidal side-effects than haloperidol and are therefore more acceptable to patients. In addition, some atypicals are associated with less post-manic depression, which can be another manifestation of extrapyramidal effects (akinetic depression). Most current guidelines for the treatment of bipolar disorder (e.g. Cookson, 2005; National Collaborating Centre for Mental Health, 2006) recommend an antipsychotic (preferably an atypical) either alone or as part of first-line treatment of mania. 


\section{Declaration of interest}

J. C. has provided advice and lectures at meetings sponsored by the manufacturers of several atypical antipsychotics, including those mentioned in this article.

\section{References}

American Psychiatric Association (1994) Diagnostic and Statistical Manual of Mental Disorders (4th edn) (DSM-IV). APA.

Baker, R. W., Tohen, M., Fawcett, J., et al (2003) Acute dysphoric mania: treatment response to olanzapine versus placebo. Journal of Clinical Psychopharmacology, 23, 132-137.

Baker, R. W., Brown, E., Akiskal, H. S., et al (2004) Efficacy of olanzapine combined with valproate or lithium in the treatment of dysphoric mania. British Journal of Psychiatry, 185, 472-478.

Bowden, C. L., Brugger, A. M., Swann, A. C., et al (1994) Efficacy of divalproex $v$. lithium and placebo in the treatment of mania. The Depakote Mania Study Group. JAMA, 271, 918-924.

Bowden, C. L., Grunze, H., Mullen, J., et al (2005) A randomized, double-blind, placebo-controlled efficacy and safety study of quetiapine or lithium as monotherapy for mania in bipolar disorder. Journal of Clinical Psychiatry, 66, 111-121.

Chou, J. C., Zito, J. M., Vitrai, J., et al (1996) Neuroleptics in acute mania: a pharmacoepidemiologic study. Annals of Pharmacotherapy, 30, 1396-1398.

Cookson, J. C. (2001) Use of antipsychotic drugs and lithium in mania. British Journal of Psychiatry, 178 (suppl. 41), s148-s156.

Cookson, J. C. (2005) Treatment of mania. In Handbook of Affective Disorders: Diagnosis and Therapeutic Approaches (eds S. Kasper \& R. Hirschfeld), pp. 157-178. Taylor \& Francis.

Cookson, J. C. (2006) Haloperidol and risperidone in mania. In Bipolar Psychopharmacotherapy: Caring for the Patient (eds H. S. Akiskal \& M. Tohen), pp. 105-124. John Wiley \& Sons.

Cookson, J. C. (2007) Mania, bipolar disorder and their treatment. In Seminars in General Adult Psychiatry (2nd edn) (eds G. Stein \& G. Wilkinson), pp. 22-47. Gaskell.

Cookson, J. C. \& Ghalib, S. (2005) The treatment of bipolar mixed states. In Bipolar Disorder: Mixed States, Rapid Cycling and Atypical Forms (eds A. Marneros \& F. Goodwin), pp. 324-352. Cambridge University Press.

Cookson, J. C., Silverstone, T. \& Wells, B. (1981) A double-blind comparative clinical trial of pimozide and chlorpromazine in mania: a test of the dopamine hypothesis. Acta Psychiatrica Scandinavica, 64, 381-397.

Cookson, J. C., Taylor, D. \& Katona, C. (2002) Placebo effects, evaluating evidence, and combining psychotherapy. In Use of Drugs in Psychiatry: The Evidence from Psychopharmacology, pp. 117-131. Gaskell.

Del Bello, M. P., Kowatch, R. A., Alder C. M., et al (2006) A double-blind randomized pilot study comparing quetiapine and divalproex for adolescent mania. Journal of the American Academy of Child and Adolescent Psychiatry, 45, 305-313.

Endicott, J. \& Spitzer, R. L. (1978) A diagnostic interview: the Schedule for Affective Disorders and Schizophrenia. Archives of General Psychiatry, 35, 837-844.

Goldsmith, D. R., Wagstaff, A. J., Ibbotson, T., et al (2003) Lamotrigine: a review of its use in bipolar disorder. Drugs, 63, 2029-2205.

Hirschfeld, R. M. A., Allen, M. H., McEvoy, J. P., et al (1999) Safety and tolerability of oral loading divalproex sodium in acutely manic bipolar patients. Journal of Clinical Psychiatry, 60, 815-818.

Hirschfeld, R., Keck, P. E., Karcher, K., et al (2004) Rapid antimanic effect of risperidone monotherapy: a 3-week multicentre, double-blind, placebo-controlled trial. American Journal of Psychiatry, 161, 1057-1065

Keck, P. E., Marcus, R., Tourkodimitris, S., et al (2003a) A placebocontrolled, double-blind study of the efficacy and safety of aripiprazole in patients with acute mania. American Journal of Psychiatry, 160, 1651-1658.
Keck, P. E. Jr., Versiani, M., Potkin, S., et al (2003b) Ziprasidone in the treatment of acute bipolar mania: a three-week, placebocontrolled, double-blind, randomized trial. American Journal of Psychiatry, 160, 741-748.

Khanna, S., Vieta, E., Lyons, B., (2005) Risperidone in the treatment of acute mania: double-blind, placebo-controlled study. British Journal of Psychiatry, 187, 229-234.

Klein, E., Bental, E., Lerer, B., et al (1984) Carbamazepine and haloperidol v placebo and haloperidol in excited psychoses. A controlled study. Archives of General Psychiatry, 41, 165-170.

McElroy, S. L., Keck, P. E. Jr, Stanton, S. P., et al (1996) A randomized comparison of divalproex oral loading versus haloperidol in the initial treatment of acute psychotic mania. Journal of Clinical Psychiatry, 57, 142-146.

McIntyre, R. S., Brecher, M., Paulsson, B., et al (2005) Quetiapine or haloperidol as monotherapy for bipolar mania: a 12-week, double-blind, randomised, parallel-group, placebo-controlled trial. European Neuropsychopharmacology, 15, 573-585.

Meehan, K., Zhang, F., David, S., et al (2001) A double-blind, randomized comparison of the efficacy and safety of intramuscular injections of olanzapine, lorazepam, or placebo in treating acutely agitated patients diagnosed with bipolar mania. Journal of Clinical Psychopharmacology, 21, 389-397.

Moller, H. J., Kissling, W., Riehl, T., et al (1989) Double-blind evaluation of the antimanic properties of carbamazepine as a comedication to haloperidol. Progress in Neuro-Psychopharmacology and Biological Psychiatry, 13, 127-136.

Muller-Oerlinghausen, B., Retzow, A., Henn, F. A., et al (2000) Valproate as an adjunct to neuroleptic medication for the treatment of acute episodes of mania: a prospective, randomized, double-blind, placebo-controlled, multicentre study. Journal of Clinical Psychopharmacology, 20, 195-203.

National Collaborating Centre for Mental Health (2006) Guideline 38: Management of Bipolar Disorder in Adults, Children and Adolescents, in Primary and Secondary Care. National Institute for Health and Clinical Excellence.

Peroutka, S. J. \& Snyder, S. H. (1980) Relationship of neuroleptic drug effects at brain dopamine, serotonin, alpha-adrenergic, and histamine receptors to clinical potency. American Journal of Psychiatry, 137, 1518-1522.

Phrolov, K., Applebaum, J., Levine, J., et al (2004) Single dose intravenous valproate in acute mania. Journal of Clinical Psychiatry, 65, 68-70.

Pope, H. G., McElroy, S. L., Keck, P. E., et al (1991) Valproate in the treatment of acute mania: a placebo-controlled study. Archives of General Psychiatry, 48, 62-68.

Potkin, S. G., Keck, P. E. Jr., Segal, S., et al (2005) Ziprasidone in acute bipolar mania: a 21-day randomized, doubleblind, placebo-controlled replication trial. Journal of Clinical Psychopharmacology, 25, 301-310.

Rifkin, A., Doddi, S., Karajgi, B., et al (1994) Dosage of haloperidol for mania. British Journal of Psychiatry, 165, 113-116.

Sachs, G. S., Sanchez, R., Marcus, R. N. et al, (2006) Aripiprazole in the treatment of acute manic or mixed episodes in patients with bipolar I disorder: a 3-week placebo-controlled study. Journal of Psychopharmacology, 20, 536-546.

Scherk, H., Pajonk, F. G. \& Leucht, S. (2007) Second-generation antipsychotic agents in the treatment of acute mania: a systematic review and meta-analysis of randomized controlled trials. Archives of General Psychiatry, 64, 442-455.

Segal, J., Berk, M. \& Brook, S. (1998) Risperidone compared with both lithium and haloperidol in mania: a double-blind randomized controlled trial. Clinical Neuropharmacology, 21, 176-180.

Smulevich, A. B., Khanna, S., Eerdekens, M., et al (2005) Acute and continuation risperidone monotherapy in bipolar mania: a 3-week placebo-controlled trial followed by a 9-week double-blind trial of risperidone and haloperidol. European Neuropsychopharmacology, 15, 75-84.

Suppes, T., Webb, A., Paul, B., et al (1999) Clinical outcome in a randomised 1-year trial of clozapine versus treatment as usual for patients with treatment-resistant illness and a history of mania. American Journal of Psychiatry, 156, 1164-1169.

Tohen, M., Sanger, T. M., McElroy, S. L., et al (1999) Olanzapine versus placebo in the treatment of acute mania. American Journal of Psychiatry, 156, 702-709. 
Tohen, M., Jacobs, T. G., Grundy, S. L., et al (2000) Efficacy of olanzapine in acute bipolar mania: a double-blind, placebocontrolled study. Archives of General Psychiatry, 57, 841-849.

Tohen, M., Baker, R. W., Altshuler, L. L., et al (2002) Olanzapine versus divalproex in the treatment of acute mania. American Journal of Psychiatry, 159, 1011-1017.

Tohen, M., Goldberg, J. F., Gonzalez-Pinto, A. M., et al (2003) A 12-week double-blind comparison of olanzapine versus haloperidol in the treatment of acute mania. Archives of General Psychiatry, 60, 1218-1226.

Tohen, M., Kryzhanovskaya, L., Carlson, G., et al (2007) Olanzapine versus placebo in the treatment of adolescents with bipolar mania. American Journal of Psychiatry, 164, 547-1556.

Tohen, M., Bowden, C. L., Smulevich, A. B., et al (2008) Olanzapine plus carbamazepine $\mathrm{v}$. carbamazepine alone in treating manic episodes. British Journal of Psychiatry, 192, 135-143.

Vieta,E., Mullen,J., Brecher, M., et al (2005) Quetiapinemonotherapy for mania associated with bipolar disorder: combined analysis of two international, double-blind, randomised, placebocontrolled studies. Current Medical Research and Opinion, 21, 923-934.

van Putten, T. \& May, R. P. (1978) "Akinetic depression" in schizophrenia. Archives of General Psychiatry, 35, 1101-1107.

Weisler, R. H., Kalali, A. H., Ketter, T. A., et al (2004) A multicentre, randomised, double-blind, placebo-controlled of extendedrelease carbamazepine capsules as monotherapy in bipolar disorder patients with manic or mixed episodes. Journal of Clinical Psychiatry, 65, 478-484.

Weisler, R. H., Keck, P. E., Swann, A. C., et al (2005) Extendedrelease carbamazepine capsules as monotherapy for acute mania in bipolar disorder: a multi-centre, randomised, doubleblind, placebo-controlled trial. Journal of Clinical Psychiatry, 66, 323-330.

Yatham, L. N., Grossman, F., Augustyns, I., et al (2003) Mood stabilisers plus risperidone or placebo Mood stabilisers plus risperidone or placebo in the treatment of acute mania in the treatment of acute mania: international, double-blind, randomised controlled trial. British Journal of Psychiatry, 182, 141-147.

Yildiz, A., Guleryuz, S., Ankerst, D. P., et al (2008) Protein kinase $C$ inhibition in the treatment of mania: a double-blind, placebocontrolled trial of tamoxifen. Archives of General Psychiatry, 65, 255-263.

Young, R. C., Biggs, J. T., Ziegler, V. E., et al (1978) A rating scale for mania: reliability, validity and sensitivity. British Journal of Psychiatry, 133, 429-435.

Zajecka, J. M., Weisler, R., Sachs, G., et al (2002) A comparison of the efficacy, safety, and tolerability of divalproex sodium and olanzapine in the treatment of bipolar disorder. Journal of Clinical Psychiatry, 63, 1148-1155.

Zarate, C. A. \& Tohen, M. (2004) Double-blind comparison of the continued use of antipsychotic treatment versus its discontinuation in remitted manic patients. American Journal of Psychiatry, 161, 169-171.

Zarate Jr, C. A., Singh, J. B., Carlson, P. J., et al (2007) Efficacy of a protein kinase $C$ inhibitor (tamoxifen) in the treatment of acute mania: a pilot study. Bipolar Disorders, 9, 561-570.

Zimbroff, D. L., Marcus, R. N., Manos, G., et al (2007) Management of acute agitation in patients with bipolar disorder: efficacy and safety of intramuscular aripiprazole. Journal of Clinical Psychopharmacology, 27, 171-176.

\section{EMIs}

\section{Theme: antipsychotics}

Options

a Haloperidol

b Risperidone

c Olanzapine

d Quetiapine

e Aripiprazole

f Ziprasidone

g Clozapine.
Choose the drug:

i which has not yet been proved superior to placebo as monotherapy for mania

ii which has failed to show superiority to placebo when combined with lithium or valproate for mania

iii which is the most commonly used for acute tranquillisation

iv which showed the lowest NNT for response in mania.

\section{Theme: anticonvulsants and lithium}

Options

a Lithium

b Valproate

c Lamotrigine

d Carbamazepine

e Topiramate

f Gabapentin.

Choose the drug:

i which, other than lithium and valproate, was efficacious as monotherapy for mania

ii with which olanzapine failed to show efficacy in mania when it was added in combination

iii which, other than lithium, has been proved efficacious in severe (psychotic) mania

iv which has the most randomised placebo-controlled trials showing efficacy in mania.

\section{Theme: symptoms and syndromes}

Options

a Depressive symptoms

b Post-manic depression

c Akinetic depression

d 'Switch' from mania to depression

e The whole range of manic symptoms

f Agitation and psychotic symptoms.

Choose the symptom or syndrome:

$i$ which is rated on the YMRS

ii which in counteracted by anticholinergic medication iii which is most common during an episode of mania iv which respond most clearly to olanzapine or quetiapine. 